\title{
MODERN PROCESSING CAPABILITIES OF ANALOG DATA FROM DOCUMENTATION OF THE GREAT OMAYYAD MOSQUE IN ALEPPO, SYRIA, DAMAGED IN CIVIL WAR
}

\author{
K.Pavelka ${ }^{a}$, J.Šedina ${ }^{\text {a }}$, P.Raeva ${ }^{a}$, M. Hůlková a \\ ${ }^{a}$ Czech Technical University in Prague, Faculty of Civil Engineering, dept. of geomatics, Thákurova 7, Prague 6, 166 29, \\ Czech Republic - pavelka@fsv.cvut.cz
}

Commission VI, WG VI/4

KEY WORDS: Syria, documentation, Aleppo, Great Omayyad mosque, analogue photos, IBMR

\begin{abstract}
:
In 1999, a big project for the documentation of the Great Omayyad mosque in Aleppo / Syria under UNESCO was conducted. By end of the last century, still analogue cameras were still being used, like the UMK Zeiss, RolleiMetric System. Digital cameras and digital automatic data processing were just starting to be on the rise and laser scanning was not relevant. In this situation, photogrammetrical measurement used stereo technology for complicated situations, and object and single-image technology for creating photoplans. Hundreds of photogrammetric images were taken. However, data processing was carried out on digital stereo plotters or workstations; it was necessary that all analogue photos were converted to digital form using a photogrammetric scanner. The outputs were adequate to the end of the last century. Nowadays, after 19 years, the photogrammetric materials still exist, but the technology and processing is completely different. Our original measurement is historical and nowadays quite obsolete. So we was it decided to explore the possibilities of the new processing of historical materials. Why? The reason is that in the last few years there has been civil war in Syria and the above mentioned monument was severely damaged. The existing historical materials therefore provide a unique opportunity for possible future reconstruction. This paper refers to the completion of existing materials, their evaluation and possibilities of new processing with today's technologies.
\end{abstract}

\section{INTRODUCTION}

\subsection{Great Omayyad mosque in Aleppo}

The Great Omayyad Mosque is one of the oldest mosques in Aleppo; it is located in the district of al-Jalloum in the local Old Town, which was in 1986 declared a World Heritage Site, near the entrance to the market (souk) Al-Madina. The place where the mosque was built was in the Hellenistic period an agora. At a time when Syria controlled the Christians, the garden of Cathedral of St. Helena was here. In the mosque that was founded by the Umayyad Caliph Suleyman at the beginning of the 8th century, the remains of St. Zacharias, the father of John the Baptist, was buried there. However, the present building, which dates from the period of the Mamluk's, was built with the exception of the minaret in the 13th century (Maysa, 1999). The original historical minaret, which fell on 24 April 2013 as a victim of the struggles of the Syrian Civil war, came from 1090, during the reign of the Seljuk Dynasty (Alafandi, Rahim, 2014).

\subsection{Old documentation}

A precise documentation is needed for any architectural analysis, proposed reconstruction and preservation of historical objects, especially buildings. Classical stereophotogrammetry was long used as an exact and precise method; however it is very time consuming in its classical form. The revolutionary step from analogical and analytical stereophotogrammetric plotters in the 70's and 80's and other technological changes in the 90's to digital photogrammetry offered new possibilities for photogrammetric processing. Digital technology entails using new instruments, technology, data storage and manipulation, and offers new possibilities for the presentation of the results. In 1998, the decision on contemporary complex documentation of the Great Omayyad Mosque in Aleppo in Syria (included into the list of the world monuments of UNESCO) was made. The documentation was carried out by the Geodezie CS firm in cooperation with CTU in Prague/laboratory of photogrammetry in 1999. Geodezie CS ensured geodetic measurement and data processing in CAD, while Czech Technical University in Prague, laboratory of photogrammetry on Faculty of Civil Engineering was responsible for the photogrammetrical part. The reason was that the Laboratory of Photogrammetry at the Czech Technical University in Prague was the largest university photogrammetric centre in the Czech Republic at the end of the last century. On an area of more than $200 \mathrm{~m} 2$, a set of special photogrammetric equipment was located for about 80 students and 5-8 Ph.D. students. The equipment involved was from a set of photogrammetric cameras; UMK, SMK and RolleiMetric for terrestrial photogrammetry. Digital cameras were in development and weren't used as a primary photogrammetric instrument. For processing, precision stereocomparators and PC-connected analogue instruments such as digital stereo equipment are used. The major work of the Photogrammetric laboratory was and still is the $3 \mathrm{D}$ measurement and documentation of historic buildings and monuments. The technology has been dramatically changed since the beginning of the new century - only digital technology was further used, direct 3D object points measurement using laser and triangulation scanners was on the rise, based on the fact that high computer performance IBMR (image based modelling and rendering) started to develop.The project in Aleppo was right at the time of major changes in technology documentation; our team used during that time the classical old analogue camera 
UMK 10/1318 (b/w planfilm13x18 cm), the RolleiMetric system (colour or $\mathrm{b} / \mathrm{w}$ roll film $6 \mathrm{~cm}$ ) and for basic documentation digital camera Olympus with 2Mpix resolution. All measurements (control points, object points etc.) were measured with a total station (Pavelka, Matoušková, 2015).

The Great Omayyad Mosque in Aleppo in Syria is included in the list of the world monuments of UNESCO. With an age of about 1000 years and a dimension of about $100 \times 60 \mathrm{~m}$, it is a very valuable object. For 3D measurement, the combination of classical geodetic measurement and photogrammetry was used. About 600 signalized control points and about 3000 object points with accuracy of less than $1 \mathrm{~cm}$ were measured from a geodetic network. About 300 photos were taken for single image and stereo processing. Softcopy photogrammetry was used with help of GIS and CAD. The complex data set with processing is about 20GB large. B/w plan-films and roll-films were developed directly in the hotel's provisional spaces (the hotel bathroom was used as a darkroom; it was necessary to have photogrammetric material before the end of the short measurement mission in Aleppo due to the low budget). As has been said, analogue images were later scanned on professional scanners such as the Nikon CoolPix (roll film) and Zeiss Intergraph (plan-films). Complex data processing - the creation of the vector model in CAD (Bentley Microstion) and photogrammetric processing to photoplans was performed in three months and was completed in 2000 (Pavelka, 2000).
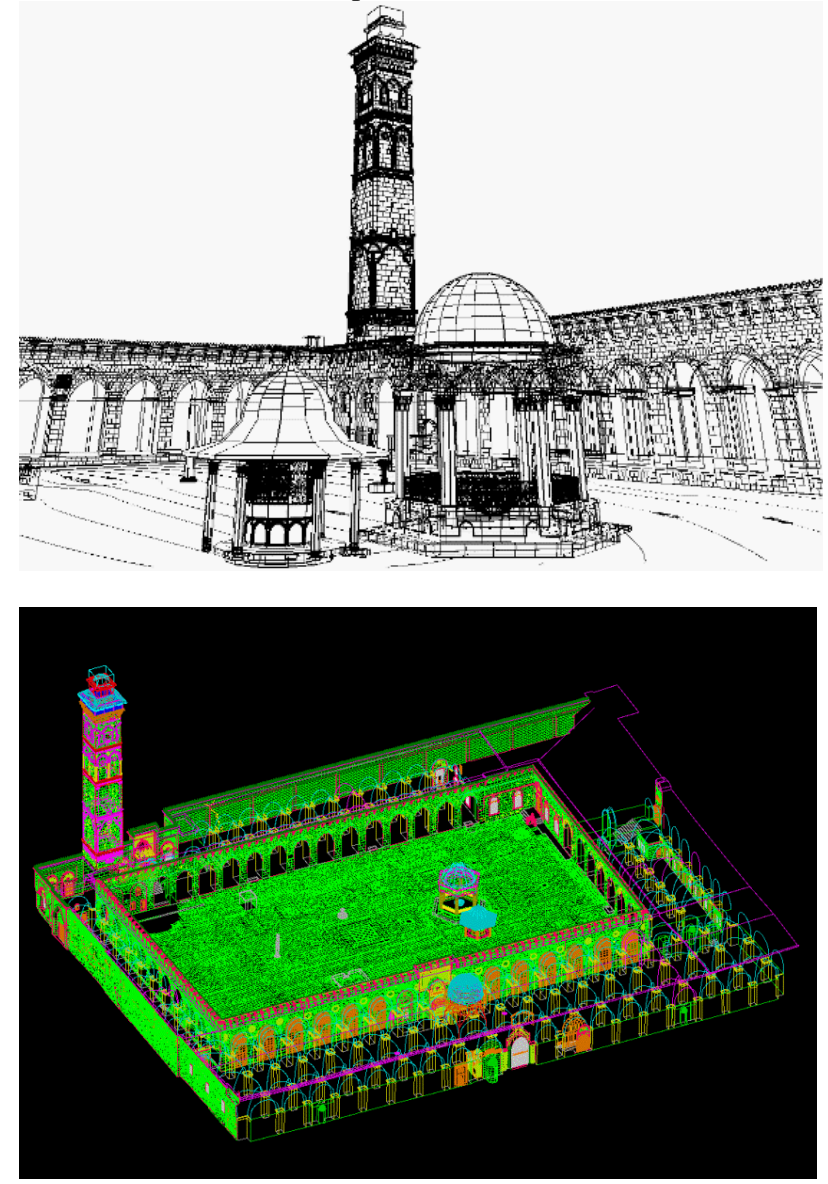

Figure 1. Perspective view on fountains (vector model) and complex documentation in vector form

\begin{tabular}{|c|c|c|c|}
\hline & UMK & RolleiMetric & Olympus \\
\hline South facade & 10 & 8 & 6 \\
\hline North facade & 9 & 9 & 27 \\
\hline
\end{tabular}

\begin{tabular}{|c|c|c|c|}
\hline East facade & 6 & - & 10 \\
\hline West facade & 5 & 5 & 17 \\
\hline $\begin{array}{c}\text { North } \\
\text { entrance }\end{array}$ & 4 & - & 8 \\
\hline Inner court & - & $22 \mathrm{~b} / \mathrm{w}$ & 26 \\
\hline
\end{tabular}

Table 1. Number of collected photos
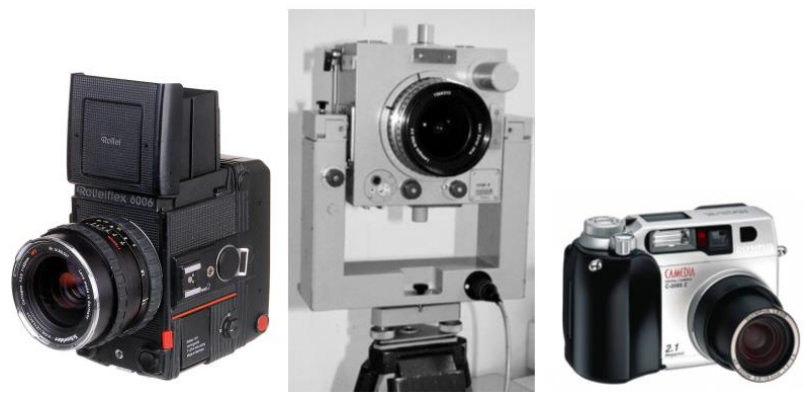

Figure 2. Used cameras in 1999: RolleiMetric 6006, UMK Zeiss 1318/10 and Olympus Camedia 2000

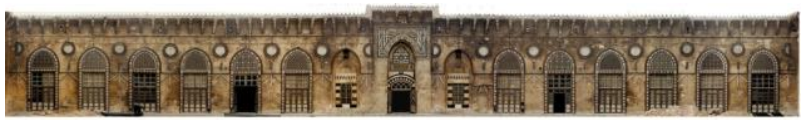

Figure 3. Example of original photoplan of façade from 1999

For the inner court, a small GIS has been created. Every layer give an information about this part of mosque.

$1^{\text {st }}$ layer: control and object points (geodetic measurement) $2^{\text {nd }}$ layer: photoplan (photogrammetric measurement and processing)

$3^{\text {rd }}$ layer: vector processing (photogrammetry and CAD)

$4^{\text {th }}$ layer: rendering $(\mathrm{CAD})$

$5^{\text {th }}$ layer: digital elevation model (DEM, raster or vector isolines)

$6^{\text {th }}$ layer: material classification
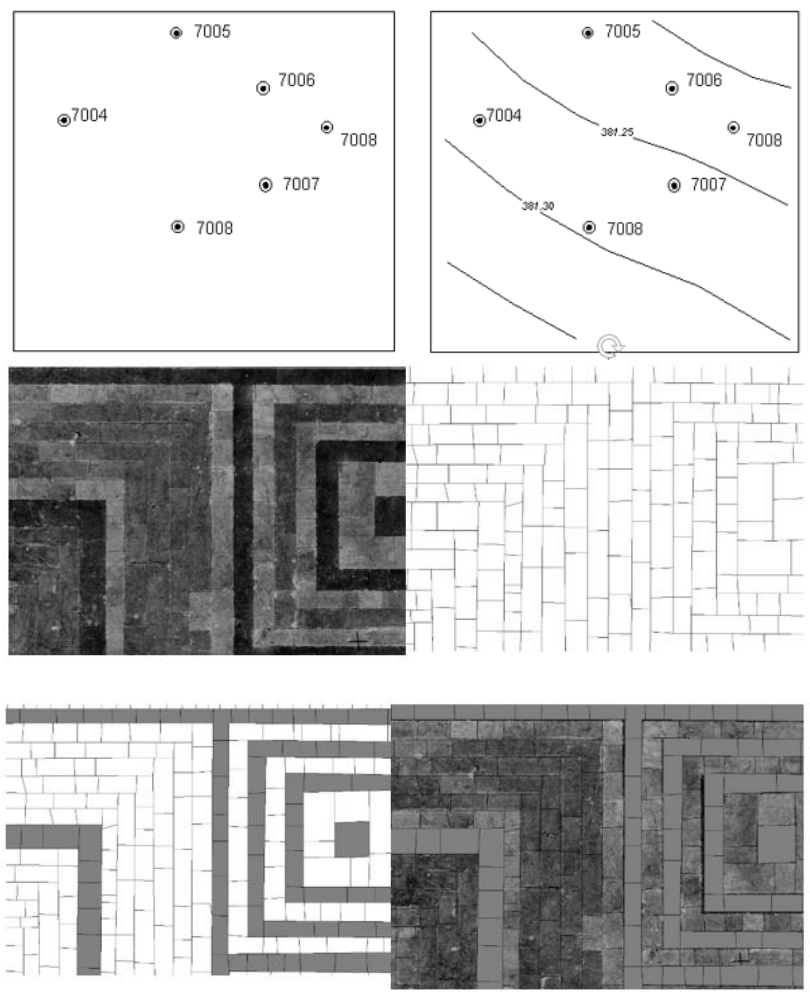

Figure 4. Mosque Inner Court - the example of layers in GIS 


\subsection{Civil War in Syria}

The war in Syria started in 2012, after tranquil demonstrations were suppressed by the military in 2011. The conflict has escalated into Civil war and to the actual fragmentation of the country into many factions fighting for various goals in a very confusing conflict. As in many others conflicts, many historical objects has been damaged or destroyed during combat, even the rare Great Omayyad mosque in Aleppo. The minaret, in which the upper part was already in poor condition, was renovated as an inner court in 2003 (Fig.46. During the fighting between the Free Syrian army and the government troops in 2012, the mosque was damaged, and on April $24^{\text {th }} 2013$ the historical minaret was destroyed. Both parties blame each other for its destruction. Unfortunately, other parts of historical mosque as the historical downtown were also damaged.
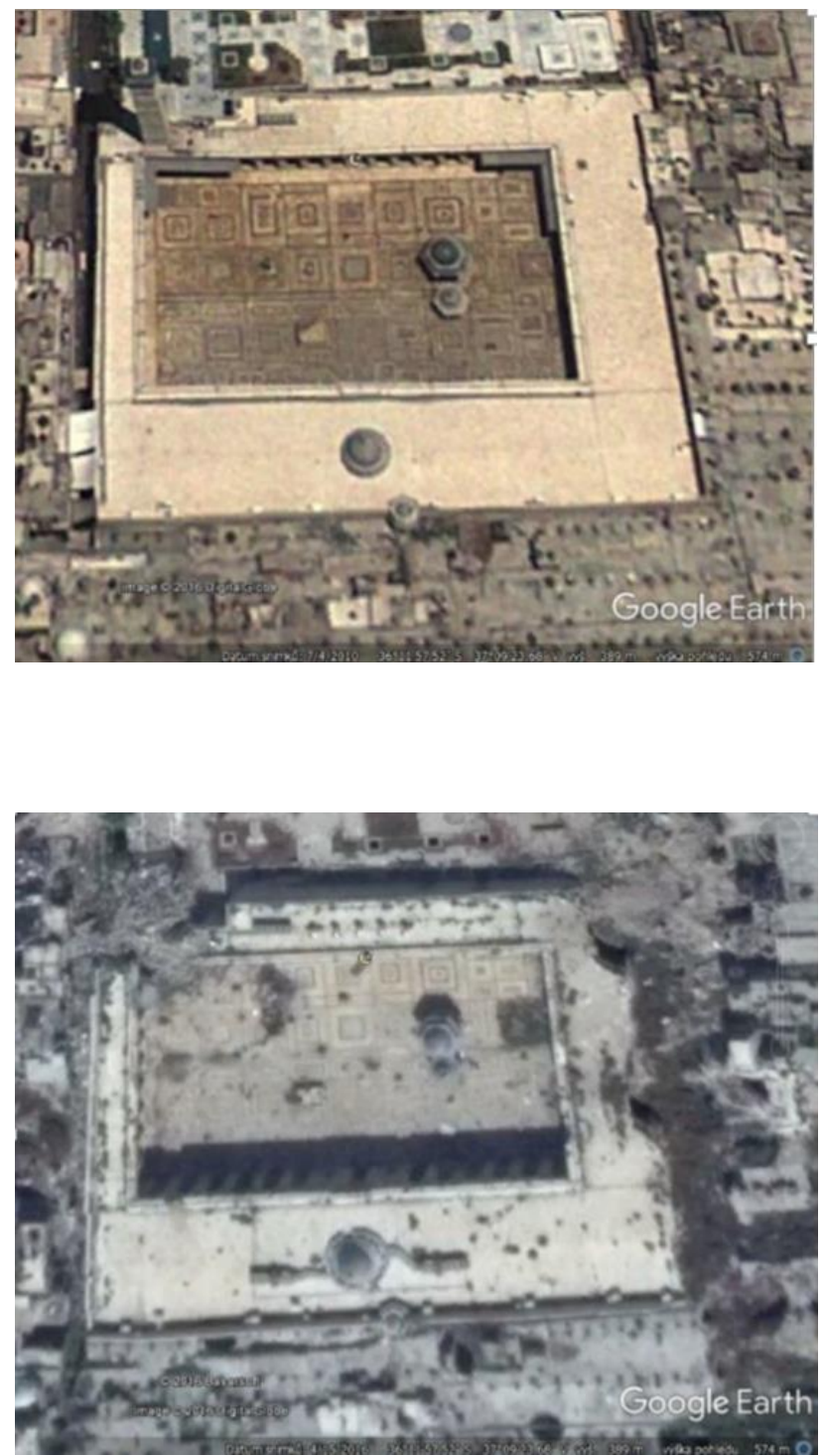

Figure 5. Great Omayyad mosque on GoogleEarth 2010 and 2016

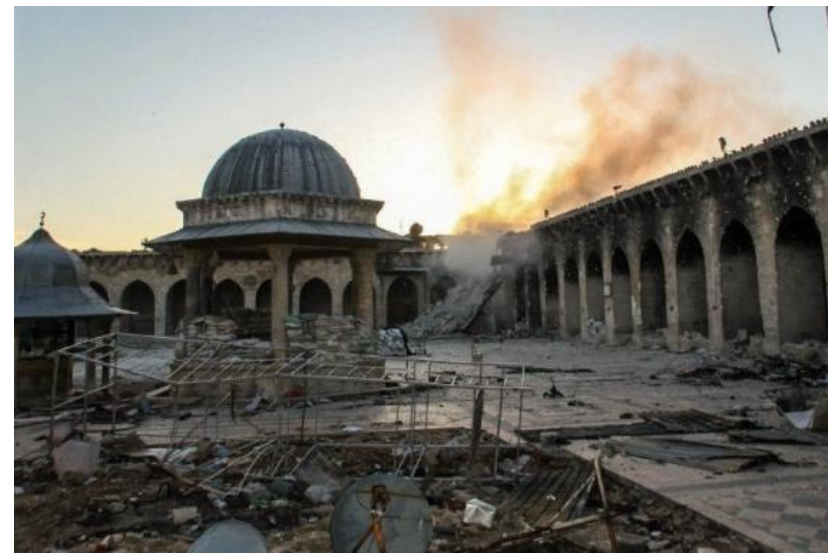

Figure 6. Destroyed minaret, 2013

\section{NEW DATA PROCESSING}

\subsection{Today's possibilities of processing}

After many years, data processing has been dramatically changed just like the situation in Syria. In 2017, we searched for archive data from 1999 and attempted a new, modern processing using the digital technology IBMR (image based modeling and rendering). From the first point of view it seemed to be a simple task. After reviewing the data, it was noted that the data had a different quality and was primarily obtained for single-image photogrammetry with minimal overlap between photographs. It meant that it was not possible to use IBMR technology, which needs a big overlap between images. Fortunately, the individual parts were photographed by different cameras (UMK 1818, RolleiMetric 80mm and Olympus digital camera) from different positions. In the case of the facades, a good database of overlapped photographs was collected, which was possible to process in Agisoft Photoscan. As a result, a true orthophoto with a pixel size of approximately $3-5 \mathrm{~mm}$ and a textured point cloud such as a 3D meshed model were produced. For orthophoto, control points were used (Tab.2), which helped create real model and Improved computation of image orientations. Some original sketches of control points were found, while others were derived from the vector model (Pavelka, Řezníček, 2011).

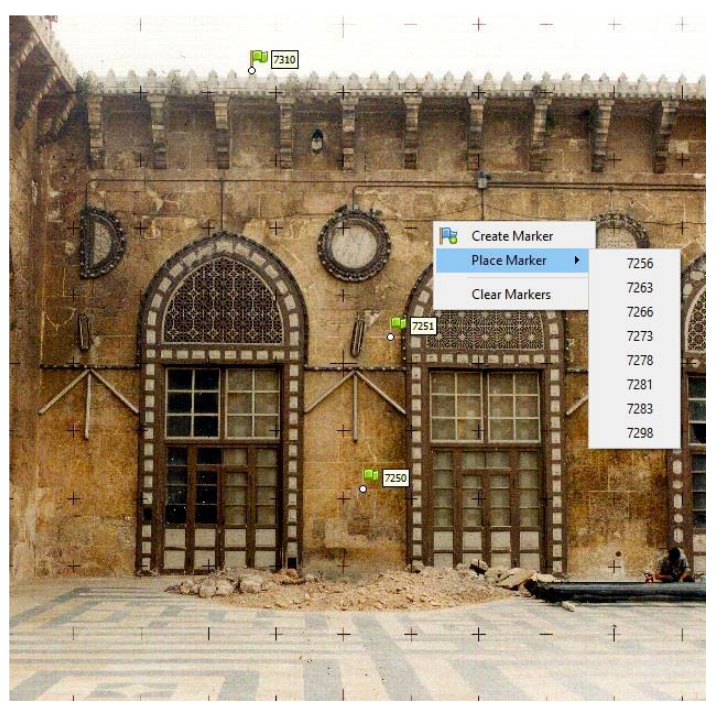

Figure 7. Original color photo from RolleiMetric 6006 camera with marked control points 


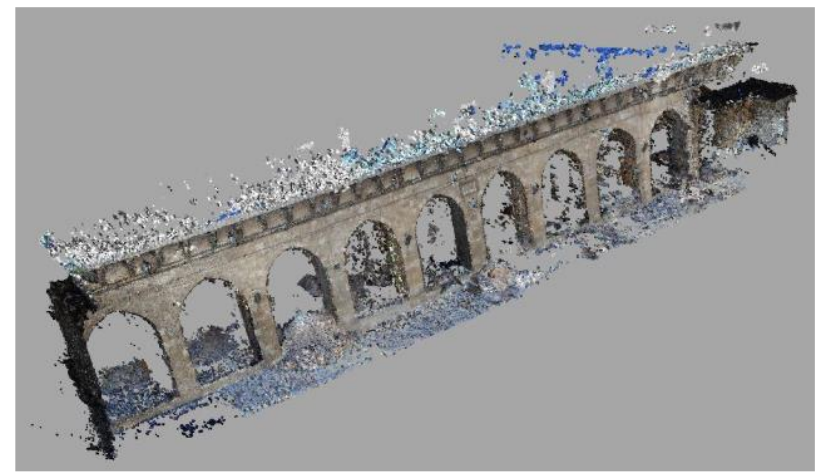

Figure 8. Sparse point cloud

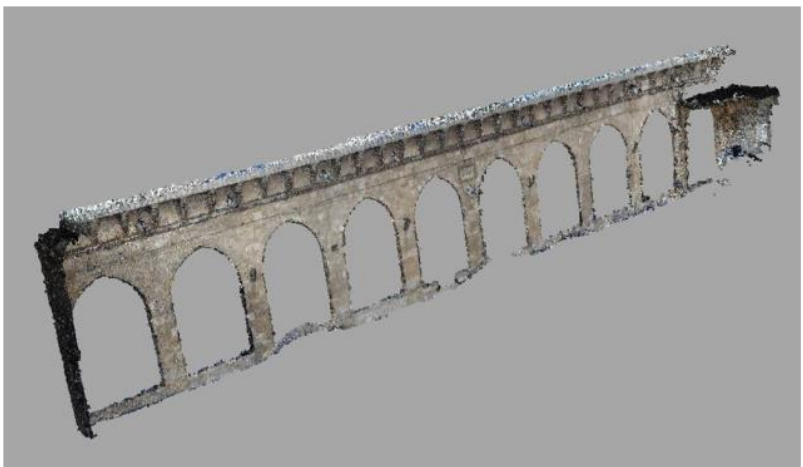

Figure 9. Cleaned point cloud

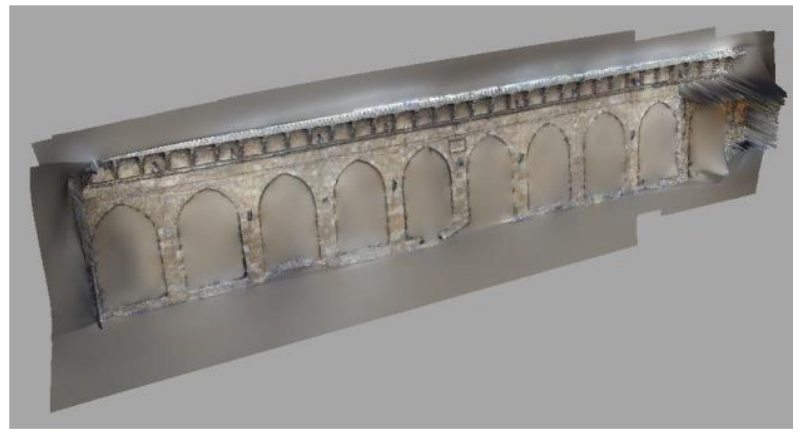

Figure 10. Meshed model of west facade

\begin{tabular}{|c|l|}
\hline & No. of used control points \\
\hline South facade & 11 \\
\hline North facade & 19 \\
\hline East facade & 11 \\
\hline West facade & 13 \\
\hline North entrance & 7 \\
\hline Inner court & 267 \\
\hline
\end{tabular}

Table 2. Used control points

After many attempts, all the images from the internal facades and the northern main entrance to the mosque were processed. There was a set of overlapped photos from three camera types; of course, the best results were achieved by using photos from the precise photogrammetric camera UMK, but these images were only $\mathrm{b} / \mathrm{w}$. After the processing of the sparse point cloud, it was necessary to erase a lot of incorrect points. After this, a good result was created for the facades such as the mesh model. After the masking of unwanted parts (peoples, things, and shadows) the true orthophoto and textured models were computed (Pavelka, Bílá,. 2013).

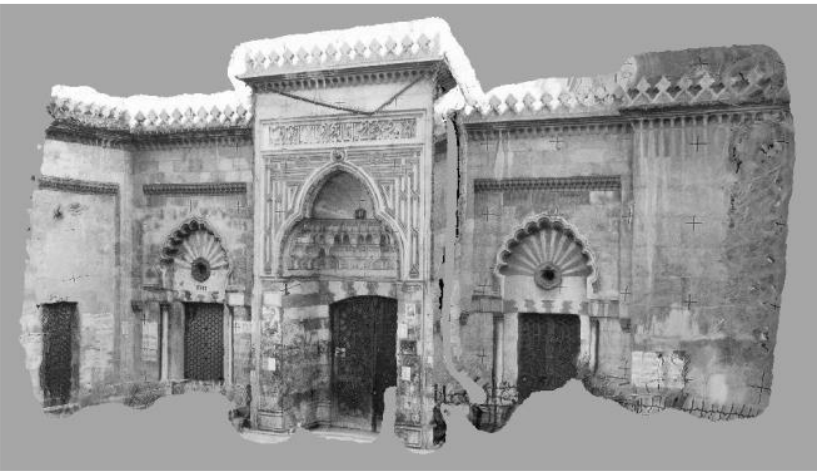

Figure 11. North entrance, textured mesh 3D model

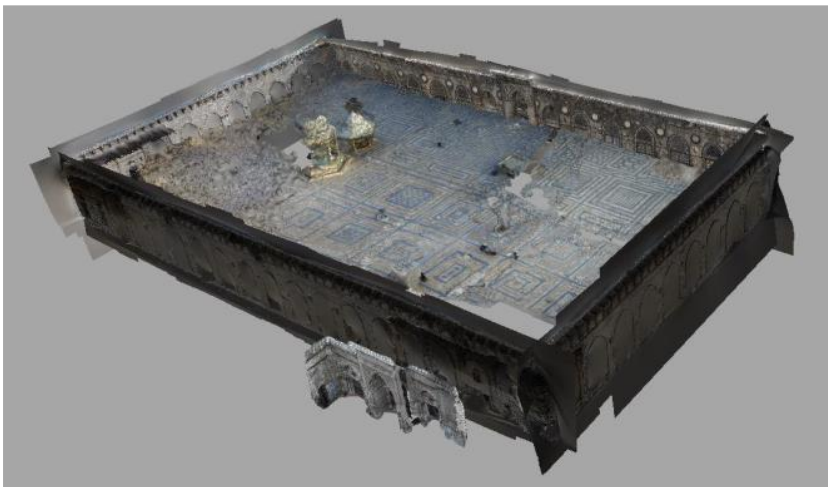

Figure 12. Complex processing of historical photographs to 3D model; inner court is after many attempt still deformed

\subsection{Results}

The Minaret was not processed to a model or point cloud due to a lack of overlapped images. Fortunately, it was very wellmodelled by G. Fangi (Fangi, 2013).

In the case of the inner court, there was a problem occurred with the preserved images. Only 22 photographs from the RolleiMertric camera were used, taken on black/white film with bad radiometric quality (unfortunately located in the inner court were many people and very dark shadows) and 26 color images taken with the Olympus camera. In the case of Olympus images, these images have only $2 \mathrm{MPix}$ geometric resolution and every image has a different internal orientation due to the zoom (these images were taken for documentation only due to low resolution). Photos were taken from the roof and from the minaret, but not good enough for IBMR technology. It meant that they were taken with a very oblique direction, with a low overlap, and in many cases against each other. In this case, the IBMR application gave very poor results or was terminated. With the RolleiMetric camera, we had calibration protocol, but it was necessary to manually make a transformation on all 121 crosses and scanned images of different sizes to crop to the same size (using outer crosses). By photos taken by with the Olympus camera, we didn't have any calibration when zoom was used. Photomodeler software was chosen as appropriate for processing and for reverse calibration computing. Hundreds of control points were used without appropriate results. Apparently it's because images with poor geometry, no quality calibration, and significantly different cameras were used. In this case, the system is very free and contains too many unknowns. 


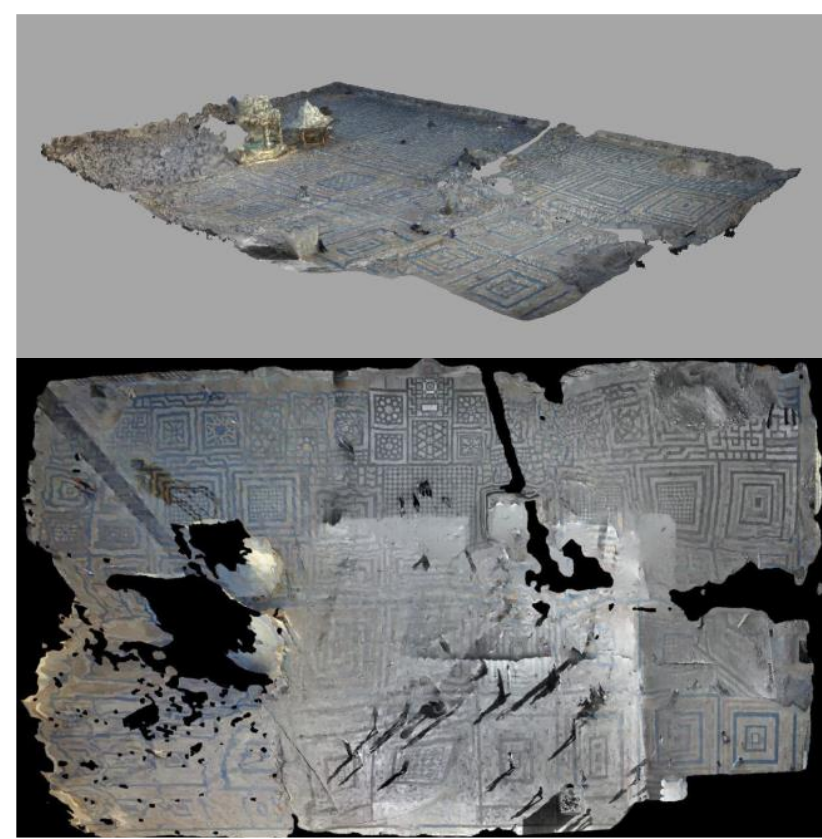

Figure 13. Distorted model of inner court

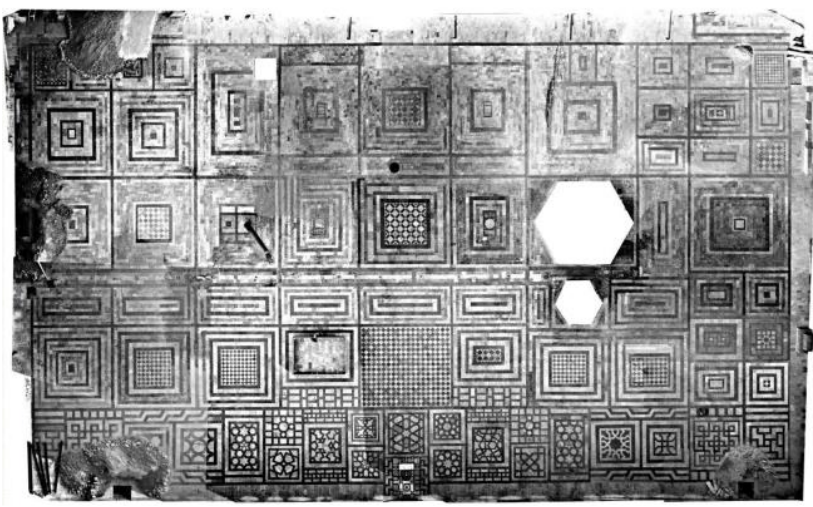

Figure 14. Original photoplan from 1999 created by single image technology with control points

After many attempts, we didn't get any good results. Intermediate results were distorted or failed to create a complex model. Results of reverse calibration were often meaningless.

\begin{tabular}{|c|l|l|l|l|}
\hline & $\begin{array}{l}\text { Tie } \\
\text { points }\end{array}$ & $\begin{array}{l}\text { Dense } \\
\text { point } \\
\text { cloud }\end{array}$ & $\begin{array}{l}\text { No. of } \\
\text { triangles } \\
\text { in mesh }\end{array}$ & $\begin{array}{l}\text { Orthophoto } \\
\text { resolution } \\
\text { [mm/pix }\end{array}$ \\
\hline $\begin{array}{c}\text { South } \\
\text { facade }\end{array}$ & 25942 & $\begin{array}{l}8598665 \\
\text { (medium) }\end{array}$ & 1693786 & 2,57 \\
\hline $\begin{array}{c}\text { North } \\
\text { facade }\end{array}$ & 25279 & $\begin{array}{l}3086110 \\
\text { (medium) }\end{array}$ & 601049 & 3,11 \\
\hline $\begin{array}{c}\text { East } \\
\text { facade }\end{array}$ & 10262 & $\begin{array}{l}4946760 \\
\text { (high) }\end{array}$ & 978480 & 4,31 \\
\hline $\begin{array}{c}\text { West } \\
\text { facade }\end{array}$ & 23952 & $\begin{array}{l}3972193 \\
\text { (high) }\end{array}$ & 778380 & 4,66 \\
\hline $\begin{array}{c}\text { North } \\
\text { entrance }\end{array}$ & 18009 & $\begin{array}{l}1845712 \\
\text { (high) }\end{array}$ & 369139 & 3,91 \\
\hline $\begin{array}{c}\text { Inner } \\
\text { court }\end{array}$ & 24718 & $\begin{array}{l}2808773 \\
\text { (high) }\end{array}$ & 561,752 & 9,05 \\
\hline
\end{tabular}

Table 3. Photogrammetric results

\section{CONCLUSION}

Type Historical data is often difficult to process with modern new technology. In this case, analogue photos of Great Omayyad mosque in Aleppo, damaged by Civil war in Syria, were used in a similar way as digital photographs from the early era of digital cameras. A good and precise vector model and historical photographs were collected from archived measurement in Aleppo in1999 for the future. This work attempted to process old photos using innovative today's technologies. Many of the existing historical photographs were used for IBMR technology. The results were quite good for data that was originally created for an entirely different image processing technology. All four inner facades of the mosque and north entrance were processed to the textured model and true ortohophotos. We will continue to experiment and process research. There is also a chance to add photos from the UMK cameras, which were aimed at the facades and contain a part of the inner court. It is possible that other photos of the mosque will be found and the object can be reconstructed better.

\section{ACKNOWLEDGEMENTS (OPTIONAL)}

This project was supported by grant of the Czech Technical University in Prague, SGS17/068/OHK1/1T/11.

\section{REFERENCES}

Alafandi, R., Rahim, A. Abdul. 2014. Umayyad mosque in Aleppo yesterday, today and tomorrow. International Journal Arts \& Sciences, 2014.

Fangi G. - Wahbeh Wissam. 2013. The destroyed minaret of the Umayyad mosque of Aleppo, the survey of the original state. European Scientific Journal. 12/2013

Maysa H. Diab. 1999. Guide to Aleppo. Avicenne Bookshop, Damascus, Syria, pp. 45

Pavelka, K, Matoušková, E. 2015. Combining Different Data Sources for City Growth Analysis and Architectural Heritage Mapping. In: Monitoring and Modeling of Global Changes: A Geomatics Perspective. Dordrecht: Springer Netherlands. 2015, pp. 37-62. 1. ISSN 2198-0721. ISBN 978-94-017-9812-9. Available from: http://link.springer.com/chapter/10.1007/97894-017-9813-6_5

Pavelka, K., Řezníček, J. 2011. New Low-cost Automated Processing of Digital Photos for Documenation and Visualisation of the Cultural Heritage, Geoinformatics. 2011, 6(6), 245-258. ISSN 1802-2669.

Pavelka, K., Bílá, Z. 2013. Use of historical images for object reconstruction. International Multidisciplinary Scientific Geoconference SGEM 2013. Albena, 16.06.2013 - 22.06.2013. Sofia: STEF92 Technology Ltd.. 2013, pp. 719-726. ISSN 1314-2704. ISBN 978-619-7105-01-8. Available from: http://sgem.org/sgemlib/spip.php?article2896

Pavelka, K. 2000. Using of Digital Photogrammetry. GIS and Internet Technology for Historical Buildings Documentation and Presentation. Technology Impact on Cultural Turism. Istanbul, Istanbul: Bogazici University. 2000, pp. 1-10. 